\title{
Multimodal imaging of Hurler syndrome- related keratopathy treated with deep anterior lamellar keratoplasty
}

Elodie Da Cunha', Cristina Georgeon ${ }^{1}$, Nacim Bouheraoua', Marc Putterman², Françoise Brignole-Baudouin ${ }^{2}$ and Vincent M. Borderie ${ }^{1 *}$ (D)

\begin{abstract}
Background: Hurler syndrome-associated keratopathy is an exceedingly rare corneal disorder that requires corneal transplantation in advanced stages. Precise assessment of the corneal condition is necessary for deciding which type of keratoplasty (i.e., deep anterior lamellar or penetrating) should be proposed. We aimed to confront the results of multimodal imaging with those of histology in a case of Hurler syndrome-associated keratopathy.

Case presentation: A 16-year-old patient with Hurler's syndrome treated with hematopoietic stem cell transplantation was referred for decreased vision related to advanced keratopathy. The patient was treated with deep anterior lamellar keratoplasty (DALK) in both eyes with uncomplicated outcome. Visual acuity improved from $0.1(20 / 200)$ preoperatively to $0.32(20 / 63)$ and 0.63 (20/32) after transplantation. The corneal endothelial cell density was 2400 cells $/ \mathrm{mm}^{2}$ in both eyes 3 years after transplantation. In vivo confocal microscopy (IVCM) and spectral domain optical coherence tomography (SD-OCT) were performed preoperatively. The corneal buttons retrieved during keratoplasty were processed for histology. In SD-OCT scans, corneal opacities appeared as diffuse stromal hyperreflectivity associated with increased corneal thickness. IVCM showed diffuse cytoplasmic granular hyperreflectivity and rounded/ellipsoid aspects of keratocytes, presence of small intracellular vacuoles, and hyperreflective epithelial intercellular spaces. Bowman's layer was thin and irregular. The corneal endothelium was poorly visualized but no endothelial damage was observed. Histology showed irregular orientation and organization of stromal lamellae, with the presence of macrophages whose cytoplasm appeared clear and granular. A perinuclear clear halo was visible within the epithelial basal cells. Bowman's layer featured breaks and irregularities.
\end{abstract}

Conclusions: The observed corneal multimodal imaging features in mucopolysaccharidosis-related keratopathy were concordant with histology. Compared with standard histology, multimodal imaging allowed additional keratocyte features to be observed. It revealed both morphological and structural changes of all corneal layers but the endothelium. This information is essential for therapeutic management which should include DALK as the firstchoice treatment in case of impaired visual acuity.

Keywords: Case report, Deep anterior lamellar keratoplasty, Hurler syndrome, In vivo confocal microscopy, Optical coherence tomography

\footnotetext{
*Correspondence: vincent.borderie@upmc.fr

'GRC32, Transplantation et Thérapies Innovantes de la Cornée, Sorbonne

université, Centre Hospitalier National d'Ophtalmologie des 15-20, 28 rue de

Charenton, 75571 Cedex 12 Paris, France

Full list of author information is available at the end of the article
}

(c) The Author(s). 2020 Open Access This article is licensed under a Creative Commons Attribution 4.0 International License, which permits use, sharing, adaptation, distribution and reproduction in any medium or format, as long as you give appropriate credit to the original author(s) and the source, provide a link to the Creative Commons licence, and indicate if changes were made. The images or other third party material in this article are included in the article's Creative Commons licence, unless indicated otherwise in a credit line to the material. If material is not included in the article's Creative Commons licence and your intended use is not permitted by statutory regulation or exceeds the permitted use, you will need to obtain permission directly from the copyright holder. To view a copy of this licence, visit http://creativecommons.org/licenses/by/4.0/ The Creative Commons Public Domain Dedication waiver (http://creativecommons.org/publicdomain/zero/1.0/) applies to the data made available in this article, unless otherwise stated in a credit line to the data. 


\section{Background}

Mucopolysaccharidosis type I (MPS I) is a very rare autosomal recessive disorder affecting lysosomal metabolism [1], with an overall prevalence of $1 / 100000$ [2]. Characterized by mutations of a ubiquitous lysosomal enzyme, $\alpha$-L-iduronidase (IDUA), which is involved in glycosaminoglycan metabolism, it leads to intra- and extracellular accumulation of dermatan and heparan sulfate which results in cell, tissue, and organ damage and dysfunction. MPS I is subdivided into 3 syndromes. Hurler syndrome (MPS IH) is the most severe form with multi-organ and progressive neurological involvement. The large clinical heterogeneity of mucopolysaccharidoses is partly explained by the large number of existing mutations, some of which permit some residual enzymatic activity [3].

The main clinical manifestations include dysmorphism, hydrocephalia, mental retardation, hepatomegaly, skeletal, cardiac, and pulmonary malformations. The main ophthalmological disorders are corneal opacities, glaucoma, retinitis pigmentosa, papillary edema, and optic nerve atrophy.

Hurler syndrome-associated keratopathy leads to impaired visual acuity in advanced stages requiring corneal transplantation to restore vision. Penetrating keratoplasty (PK) and deep anterior lamellar keratoplasty (DALK) can be proposed with known advantages associated with the latter technique, such as lower rejection risk and higher survival of the corneal endothelium. Precise assessment of the corneal condition is necessary for deciding which type of keratoplasty should be proposed. Successful DALK surgery in MPS I has been reported in 4 patients, whereas reported data concerning PK in MPS I is only poor with graft failure observed in 2 out of 3 patients [4-8].

Corneal multimodal imaging, combining in vivo confocal microscopy (IVCM) and spectral domain optical coherence tomography (SD-OCT), is an essential tool for the diagnosis and characterization of many ocular surface diseases $[9,10]$. To our knowledge this approach has not been reported yet to assess Hurler syndromeassociated keratopathy. We report multimodal imaging and histology of the cornea in a patient with Hurler syndrome who underwent deep anterior lamellar keratoplasty (DALK).

\section{Case presentation}

A 16-year-old female patient with Hurler's syndrome treated with hematopoietic stem cell transplantation was referred for decreased vision. The diagnosis had been made by quantification of $\alpha$-l-iduronidase and gene sequencing. Systemic disorders in this pediatric patient included dysostosis, arachnoid cysts and sleep apnea. Corrected visual acuity was $0.1(20 / 200)$ in both eyes. Slit lamp examination revealed diffuse, whitish, milky, full-thickness stromal opacities (Fig. 1). Intraocular pressure was $28 \mathrm{mmHg}$ in both eyes. Corneal hysteresis was increased (Corneal Hysteresis, 18.6/20.9 mmHg; Corneal Resistance Factor, $20.7 / 21.5 \mathrm{mmHg}$ ) and corrected intraocular pressure (IOPcc) provided by the ORA device (Reichert, Inc., Depew, NY) was normal $(17 / 11 \mathrm{mmHg})$. Fundus was unremarkable and electrophysiological examinations were within normal limits (ERG, response to the lower limit of normal with no overall deficit; PEV, no major conduction disorders in the visual pathways). No history or evidence of optic nerve involvement was found in this patient.

A DALK was performed in the left eye and, 3 years later, in the right eye. A type 1 big bubble was obtained after air injection in the posterior stroma [11]. The posterior bed consisted of the predescemetic Dua's layer in the $6-\mathrm{mm}$ central zone and the posterior stroma in the $6-8.25 \mathrm{~mm}$ peripheral zone. An $8.25-\mathrm{mm}$ graft was sutured after Descemet's membrane removal using a combination of 8 interrupted sutures and 16-bit running suture. Long-term followup was unremarkable, i.e., clear grafts, improved vision, normal intraocular pressure, no rejection episodes. Four years after left eye transplantation, visual acuity was $0.32(20 / 63$, RE) and 0.63 (20/32, LE). Central corneal thickness (CCT) was normal (RE, $530 \mu \mathrm{m}$; LE, $520 \mu \mathrm{m}$ ). The corneal endothelial cell density was 2400 cells $/ \mathrm{mm}^{2}$ in both eyes. The patient was satisfied with the results of transplantation which provided her with improved quality of life (Table 1).

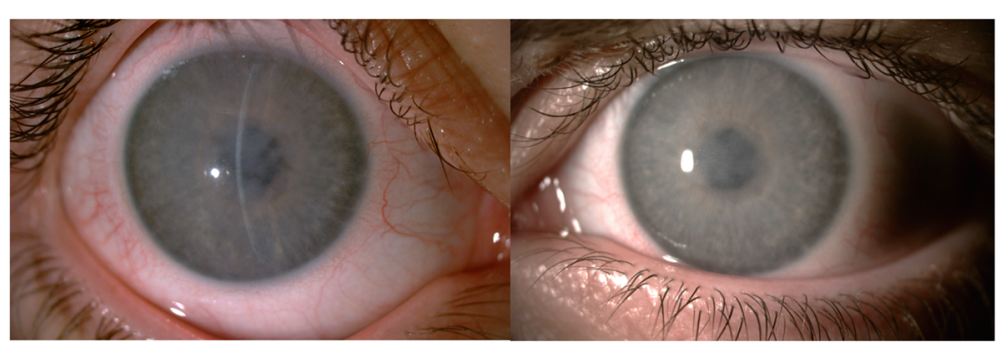

Fig. 1 Hurler syndrome-associated keratopathy observed with slit-lamp 
Table 1 Shows a timeline of the episode of care

\begin{tabular}{llll}
\hline Time point (year) & Patient age (years) & Intervention & Workup \\
\hline 0 & 16 & DALK, LE & Visual acuity, slit-lamp, SD-OCT, IVCM \\
1 & 17 & Visual acuity, slit-lamp, SD-OCT, SM \\
2 & 18 & Visual acuity, slit-lamp, SD-OCT, SM \\
3 & 19 & Visual acuity, slit-lamp, SD-OCT, SM \\
4 & 20 & VALK, RE & Visual acuity, slit-lamp, SD-OCT, SM \\
\hline $\begin{array}{l}\text { DALK deep anterior lamellar keratoplasty, IVCM in vivo confocal microscopy, LE left eye, RE right eye, SD-OCT spectral domain optical coherence tomography, SM } \\
\text { specular microscopy }\end{array}$
\end{tabular}

Preoperatively corneas were assessed with SD-OCT (RTVue-100@, Optovue Inc., Fremont, CA) and In vivo confocal microscopy (Heidelberg Retina Tomograph II/ Rostock Cornea Module, Heidelberg Engineering GmbH, Heidelberg, Germany). Corneal buttons obtained during keratoplasty were processed for histology and stained with hematoxylin-eosin-safran, Schiff periodic acid, and Masson's trichrome.

SD-OCT showed diffuse hyperreflectivity with normal endothelial reflectivity. CCT was $695 \mu \mathrm{m}$ in the right eye and $662 \mu \mathrm{m}$ in the left eye (Fig. 2a).

In Vivo Confocal Microscopy was performed by a trained senior orthoptist. It showed changes in corneal layers including diffuse hyperreflectivity of the corneal epithelium, presence of granulations within the epithelial intercellular spaces, sub-basal nerve plexus irregularity and rarefaction, hyperreflective keratocytes featuring morphological changes (i.e., round or ellipsoid shape, activated keratocytes, granular cytoplasm, presence of small dark intracellular images forming intracytoplasmic vacuoles) (Fig. 2b, c, g, h, i). Vacuoles were located close to the keratocyte nuclei. Hyperreflective deposits were observed in the anterior stroma associated with changes in Bowman's layer, which appeared irregular and thinner (Fig. 2d-e). Stromal opacification resulted in poor endothelial cell visualization. No damage to the corneal endothelium was found.

Histology (Fig. 2f) showed no differences between fellow corneas. The superficial epithelial cells appeared normal. Basal epithelial cells were distributed in different planes. They featured a perinuclear clear halo. Bowman's layer was irregular with variable thickness and presence

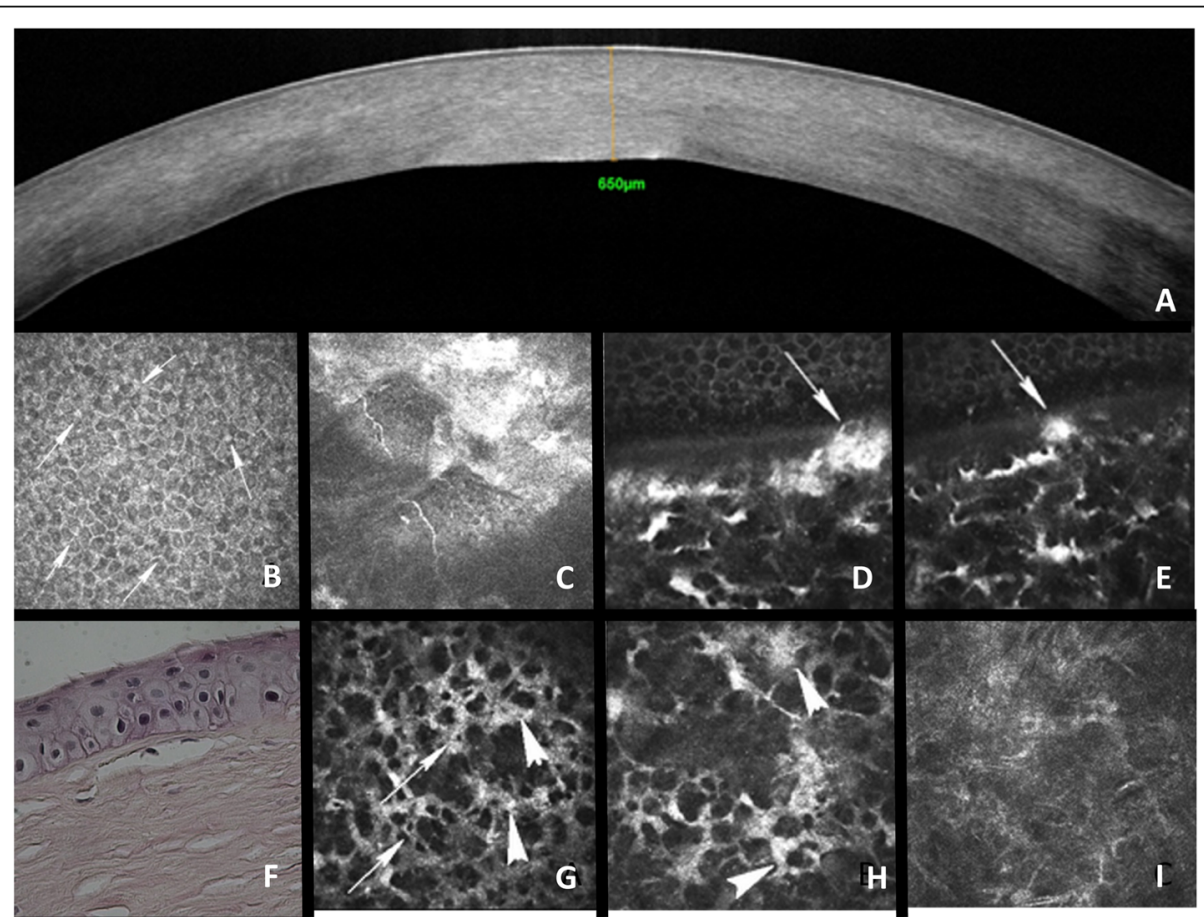

Fig. 2 Multimodal imaging and histology of Hurler syndrome-associated keratopathy. Both extracellular (arrows) and intracellular (arrowheads) deposits are observed. a SD-OCT cross-section. b-e IVCM of the corneal epithelium and anterior stroma. $\mathbf{f}$ histology. g-i IVCM of the corneal stroma 
of isolated keratocytes just below Bowman's layer. Stromal changes were mainly located in its anterior part, including irregular lamellae, presence of clear cytoplasmic mononuclear macrophage cells, and PAS-positive granulations.

\section{Conclusions}

In our patient, SD-OCT showed diffuse hyperreflectivity, uniformly distributed across the entire corneal thickness and associated with increased CCT. Ahmed et al. [12] found OCT to be useful in mucopolysaccharidosis for assessing CCT and anatomy of the iridocorneal angle. Age-dependent increase in CCT was reported in all mucopolysaccharidosis. Other studies did not find this correlation [13].

We observed changes affecting all layers in In vivo confocal microscopy, with diffuse hyperreflectivity and granular hyperreflectivity between epithelial cells. The latter has been previously reported in MPS IS and MPS I-HS [14, 15], demonstrating epithelial involvement in MPSs. In histopathology we observed alterations in the basal epithelial layer with perinuclear halo as reported by others in MPS I-S [16] and MPS I-HS [15]. Conversely, Huang et al. [17] reported unremarkable corneal epithelium. Keratocyte changes included rounded ellipsoid shape, hyperreflective cytoplasm, and intracytoplasmic vacuoles $[14,15]$ in accordance with histology, which demonstrates intra- and extracellular accumulation of glycosaminoglycans [17]. Stromal deposits are associated with increased variability of both fibril diameter and inter-fibril distance and the presence of longspacing collagen fibrils that contribute to stromal opacification $[17,18]$.

Contribution of In vivo confocal microscopy to corneal endothelium assessment before keratoplasty is limited by poor visualization of endothelial cells. No damage to the corneal endothelium was found in our patient. Nevertheless, SD-OCT showed normal endothelial reflectivity. Endothelial involvement in MPS is controversial and probably depends on the disease stage. In histology, endothelial intracellular vacuoles are not constant [1517]. Our patient featured unremarkable preoperative endothelial assessment, both with IVCM and SD-OCT. Post-operative specular microscopy confirmed the absence of endothelial damage and normal endothelial function.

Enzyme replacement therapy and hematopoietic stem cell transplantation are the major treatments of mucopolysaccharidoses [19]. However, their effect on corneal opacification remains controversial [20-22]. In addition, retinal involvement may progress with time after hematopoietic stem cell transplantation [22]. Keratoplasty is the reference treatment of severe corneal opacification, allowing visual rehabilitation if retinal function is maintained. Favorable results were reported after penetrating keratoplasty [23]. However, as MPSs mainly involve epithelium and stroma, DALK seems more suitable in young patients [24] because it reduces the risk of endothelial rejection. Few DALK cases (8 eyes from 4 patients) have been reported in mucopolysaccharidosis patients [4-6]. Our patient presented good visual recovery, uneventful outcome, and absence of corneal opacity recurrence. Similar results were reported in a series of 4 eyes from 2 patients with Hurler's syndrome and Hurler-Scheie syndrome and in a patient with HurlerScheie syndrome undergoing concurrent enzyme replacement therapy $[5,6]$.

Multimodal imaging of mucopolysaccharidosis-related keratopathy revealed both morphological and structural changes of all corneal layers but the endothelium. This information is relevant for therapeutic management which should include DALK as the first-choice treatment in case of impaired visual acuity.

\section{Abbreviations \\ DALK: Deep anterior lamellar keratoplasty; IVCM: In vivo confocal microscopy; LE: Left eye; MPS: Mucopolysaccharidosis; RE: Right eye; SD-OCT: Spectral} domain optical coherence tomography; SM: Specular microscopy

\section{Acknowledgements \\ None.}

\section{Authors' contributions}

Design and conduct of the study: (VMB, EDC). Collection, management, analysis, and interpretation of the data: (EDC, CG, NB, MP, FBB, VMB). Preparation of the manuscript: (EDC, VMB). Review and approval of the manuscript: (EDC, CG, NB, MP, FBB, VMB). All authors have read and approved the manuscript.

\section{Funding}

The research was funded by an ANR PRTS Grant (ANR-13-PRTS-0009; Paris, France). The funder was not involved in the manuscript writing, editing, approval, or decision to publish.

Availability of data and materials

Anonymized data used to support the findings of this study are available from the corresponding author upon request.

Ethics approval and consent to participate

Informed consent was obtained before surgery.

Consent for publication

The patient gave written informed consent to publish this case report.

\section{Competing interests}

EDC, no financial disclosures. CG, no financial disclosures. NB, no financial disclosures. MP, no financial disclosures. FBB, no financial disclosures. VMB, no financial disclosures.

\section{Author details}

1GRC32, Transplantation et Thérapies Innovantes de la Cornée, Sorbonne université, Centre Hospitalier National d'Ophtalmologie des 15-20, 28 rue de Charenton, 75571 Cedex 12 Paris, France. ${ }^{2}$ Laboratoire (2), Centre Hospitalier National d'Ophtalmologie des 15-20, Paris, France. 
Received: 14 July 2020 Accepted: 8 October 2020

Published online: 31 October 2020

\section{References}

1. Ashworth JL, Biswas S, Wraith E, Lloyd IC. Mucopolysaccharidoses and the eye. Surv Ophthalmol. 2006;51:1-17. https://doi.org/10.1016/j.survophthal.2005.11.007.

2. Moore D, Connock MJ, Wraith E, Lavery C. The prevalence of and survival in mucopolysaccharidosis I: Hurler, Hurler-Scheie and Scheie syndromes in the UK. Orphanet J Rare Dis. 2008;3:24. https://doi.org/10. 1186/1750-1172-3-24.

3. Scott HS, Bunge S, Gal A, Clarke LA, Morris CP, Hopwood JJ. Molecular genetics of mucopolysaccharidosis type I: diagnostic, clinical, and biological implications. Hum Mutat. 1995;6:288-302. https://doi.org/10.1002/humu. 1380060403

4. Sati A, Ramappa M, Chaurasia S, Prasad SM. Deep anterior lamellar keratoplasty in case of Hurler-Scheie syndrome. BMJ Case Rep. 2014. https:// doi.org/10.1136/bcr-2013-202730.

5. da Silva Ricardo JR, Medhi J, Pineda R. Indications for and outcomes of deep anterior lamellar keratoplasty in mucopolysaccharidoses. J Pediatr Ophthalmol Strabismus. 2013;50:376-81.

6. Eah KS, Lee CM, Kim MJ. Deep anterior lamellar keratoplasty in a case of Hurler-Scheie syndrome undergoing enzyme replacement therapy. Cornea. 2019;38:376-8. https://doi.org/10.1097/ICO.0000000000001840.

7. Karadag R, Rapuano CJ, Hammersmith KM, Nagra PK. Causes of congenital corneal opacities and their management in a tertiary care center. Arq Bras Oftalmol. 2020:83:98-102. https://doi.org/10.5935/0004-2749.20200023.

8. Burillon C, Pey C, Durand L. Penetrating keratoplasty and corneal dystrophy in Scheie's syndrome. J Fr Ophtalmol. 1989;12:561-8.

9. Jalbert I, Stapleton F, Papas E, Sweeney DF, Coroneo M. In vivo confocal microscopy of the human cornea. Br J Ophthalmol. 2003;87: 225-36.

10. Siebelmann S, Scholz P, Sonnenschein S, et al. Anterior segment optical coherence tomography for the diagnosis of corneal dystrophies according to the IC3D classification. Surv Ophthalmol. 2018;63:365-80. https://doi.org/ 10.1016/j.survophthal.2017.08.001.

11. Borderie VM, Werthel AL, Touzeau O, Allouch C, Boutboul S, Laroche L. Comparison of techniques used for removing the recipient stroma in anterior lamellar keratoplasty. Arch Ophthalmol. 2008;126:31-7.

12. Ahmed TY, Turnbull AM, Attridge NF, et al. Anterior segment OCT imaging in mucopolysaccharidoses type I, II, and VI. Eye (Lond). 2014;28:327-36. https://doi.org/10.1038/eye.2013.281.

13. Connell P, McCreery K, Doyle A, Darcy F, O'Meara A, Brosnahan D. Central corneal thickness and its relationship to intraocular pressure in mucopolysaccararidoses-1 following bone marrow transplantation. J AAPOS 2008;12:7-10. https://doi.org/10.1016/j.jaapos.2007.04.003.

14. Grupcheva CN, Craig JP, McGhee CN. In vivo microstructural analysis of the cornea in Scheie's syndrome. Cornea. 2003;22:76-9.

15. Aragona P, Wylegala E, Wroblewska-Czajka E, et al. Clinical, confocal, and morphological investigations on the cornea in human mucopolysaccharidosis IH-S. Cornea. 2014;33:35-42. https://doi.org/ 10.1097/ICO.0000000000000005.

16. Rummelt V, Meyer HJ, Naumann GO. Light and electron microscopy of the cornea in systemic mucopolysaccharidosis type I-S (Scheie's syndrome). Cornea. 1992;11:86-92.

17. Huang $Y$, Bron AJ, Meek KM, Vellodi A, McDonald B. Ultrastructural study of the cornea in a bone marrow-transplanted Hurler syndrome patient. Exp Eye Res. 1996;62:377-87. https://doi.org/10.1006/exer.1996. 0043

18. Alroy J, Haskins M, Birk DE. Altered corneal stromal matrix organization is associated with mucopolysaccharidosis I, III and VI. Exp Eye Res. 1999;68: 523-30. https://doi.org/10.1006/exer.1998.0622

19. Grewal SS, Wynn R, Abdenur JE, et al. Safety and efficacy of enzyme replacement therapy in combination with hematopoietic stem cell transplantation in Hurler syndrome. Genet Med. 2005;7:143-6. https://doi. org/10.1097/01.GIM.0000154299.22120.6A.

20. Wraith JE. The first 5 years of clinical experience with laronidase enzyme replacement therapy for mucopolysaccharidosis I. Expert Opin Pharmacother. 2005:6:489-506. https://doi.org/10.1517/14656566.6.3. 489.

21. Ferrari S, Ponzin D, Ashworth $J$, et al. Diagnosis and management of ophthalmological features in patients with mucopolysaccharidosis.
Br J Ophthalmol. 2011;95:613-9. https://doi.org/10.1136/bjo.2010. 179937.

22. Gullingsrud EO, Krivit W, Summers CG. Ocular abnormalities in the mucopolysaccharidoses after bone marrow transplantation. Longer followup. Ophthalmology. 1998;105:1099-105. https://doi.org/10.1016/S01616420(98)96014-6.

23. Bothun ED, Decanini A, Summers CG, Orchard PJ, Tolar J. Outcome of penetrating keratoplasty for mucopolysaccharidoses. Arch Ophthalmol. 2011;129:138-44. https://doi.org/10.1001/archophthalmol.2010.341.

24. Harding SA, Nischal KK, Upponi-Patil A, Fowler DJ. Indications and outcomes of deep anterior lamellar keratoplasty in children. Ophthalmology. 2010;117: 2191-5. https://doi.org/10.1016/j.ophtha.2010.03.025

\section{Publisher's Note}

Springer Nature remains neutral with regard to jurisdictional claims in published maps and institutional affiliations.
Ready to submit your research? Choose BMC and benefit from:

- fast, convenient online submission

- thorough peer review by experienced researchers in your field

- rapid publication on acceptance

- support for research data, including large and complex data types

- gold Open Access which fosters wider collaboration and increased citations

- maximum visibility for your research: over $100 \mathrm{M}$ website views per year

At $\mathrm{BMC}$, research is always in progress.

Learn more biomedcentral.com/submissions 